\title{
Grain size variation in the swash zone of Lhoong Beach, Aceh Besar
}

\author{
Khairul Akbar ${ }^{1}$, Chitra Octavina $^{1,2}$, and Syahrul Purnawan ${ }^{1 *}$ \\ ${ }^{1}$ Department of Marine Sciences, Faculty of Marine and Fisheries, Universitas Syiah Kuala, Banda Aceh 23111, Indonesia \\ ${ }^{2}$ Laboratory of Marine Biology, Faculty of Marine and Fisheries, Universitas Syiah Kuala, Banda Aceh 23111, Indonesia
}

\begin{abstract}
The spatio-temporal texture characteristics are key parameters for understanding the dynamics of the sedimentary environment. This study was conducted to determine the sediment characteristics in swash zone of Lhoong Beach, Aceh Besar Regency. The analysis emphasizes the seasonal variation of sediment mean grain size (MGS) based on vertical stratification. Sediment samples were taken during November 2018, January 2019 and March 2019, from 3 stations. Samples from station 3 had the coarsest grain characteristics, where the highest MGS value at station 3 was recorded in the mid-layer $(5-10 \mathrm{~cm})$ in November. The grain size was found to vary with changing seasons and the depth of the sediment layer. Based on depth stratification, the highest standard deviation was obtained by the mid-layer $(5-10 \mathrm{~cm})$; while by period, the highest standard deviation of the MGS value was generated during November.
\end{abstract}

\section{Introduction}

Coastal areas are one of the most dynamic areas on the earth's surface [1]. The interaction between land and sea will form a unique morphology in each coastal area [2][6]. As a dynamic zone, the coastal zone does not only affect physical factors, but also biology [7], [8] and chemistry [9]. A number of parameters that can affect changes in coastal physical conditions, including: currents, waves, tides, storms, and landscapes [10]-[12].

In general, seasons play a major role in controlling energy in the aquatic environment [13], [14], where in coastal areas seasonal changes result in variations in the strength and intensity of waves on the coast [15]. So it can be further explained that seasonal variations can affect the grain size of sediment through waves on the coast [16]. In particular, several researchers also studied the effect of waves in swash areas on sediment profiles [17], [18].

Although seasons are widely studied for their influence on coastal dynamics in general, specific observations of grain size can be the focus for observing the impact of seasonal changes on coastal conditions [19]. The grain size study of coastal sediments provides information about the intrinsic properties of sediments and their depositional environment [20]. Complex coastal processes operating in the past and in the present have left their traces in sediments [21], [22]. In this regard, coastal sedimentology plays an important role in documenting the depositional history of an aquatic environment [14], [23], [24]. A granulometric study of the Aceh coast has been carried out by several researchers [25], [26]. However, as an area bordering the Indian Ocean, the condition of the west coast of Aceh has a fairly large seasonal variation [27]. It is then suspected that seasonal variations also have an influence on sediment grains on the Lhoong beach, Aceh Besar. Furthermore, this study also provides an overview of vertical changes to changes in sediment character to a depth of $15 \mathrm{~cm}$.

\section{Material dan Method}

The research took place on the Lhoong beach, Aceh Besar District. Lhoong Beach is an open sand beach, facing the Indian Ocean. Sediment sampling was carried out at three stations which were $1.2 \mathrm{~km}$ apart from each station (Figure 1). The sampling area was defined in the foreshore area, also known as the swash zone, specifically at the low tide boundary.

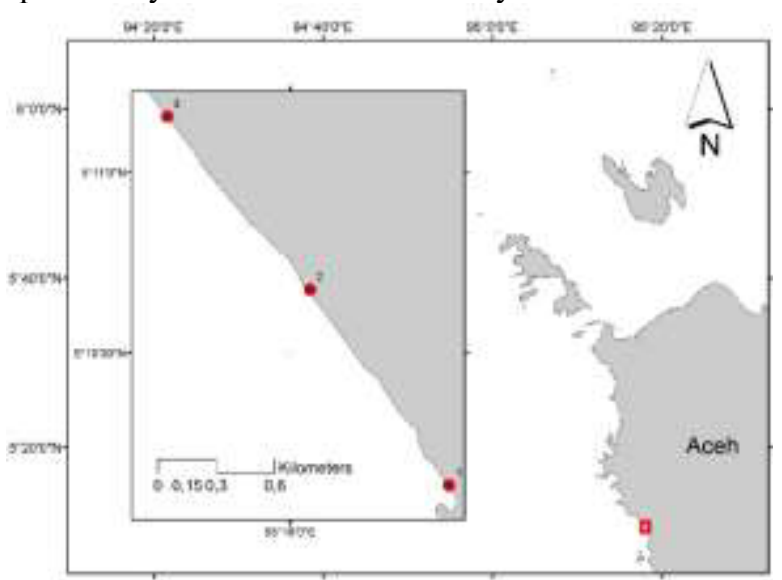

Fig. 1. Sampling location in Lhoong Beach, Aceh Province

Sediment collection was carried out using the coring method to a depth of $15 \mathrm{~cm}$ [28], whereupon the sample

*Corresponding author: syahrulpurnawan@unsyiah.ac.id 
was further processed by dividing it into three layers, each layer having a thickness of $5 \mathrm{~cm}$ : i.e. upper layer $(0-5 \mathrm{~cm})$, mid-layer $(5-10 \mathrm{~cm})$, and lower layer $(10-15$ $\mathrm{cm})$. Data collection was carried out in November 2018, January 2019 and March 2019.

The grain size data analysis was carried out using a wet sieve method, using a stratified sieve. A total of approximately 200 grams of sample was separated based on the mesh size of $2 \mathrm{~mm} ; 1 \mathrm{~mm} ; 0.5 \mathrm{~mm} ; 0.25 \mathrm{~mm}$; $0.125 \mathrm{~mm} ; 0.063 \mathrm{~mm} ; 0.038 \mathrm{~mm}$. Size classification follows the Wentworth scale [29]. The calculation of the percentage weight percent of sediment can be known from the weight of each sediment fraction (eq. 1), and then the mean grain size of the sediment $\left(\bar{x}_{a}\right)$ (eq. 2$)$ is calculated using the following equation:

Class weight $(i)(\%)=\frac{\text { weight size }(i)}{\text { total sample weight }} \times 100 \%$

$\bar{\chi}_{a}=\sum_{i=1}^{n} \frac{(\text { class weight }(i) \times \text { mesh size }(i))}{n}$

\section{November}

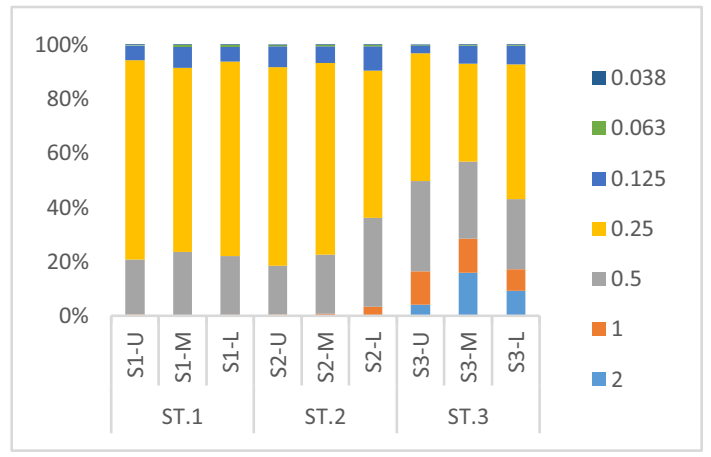

January
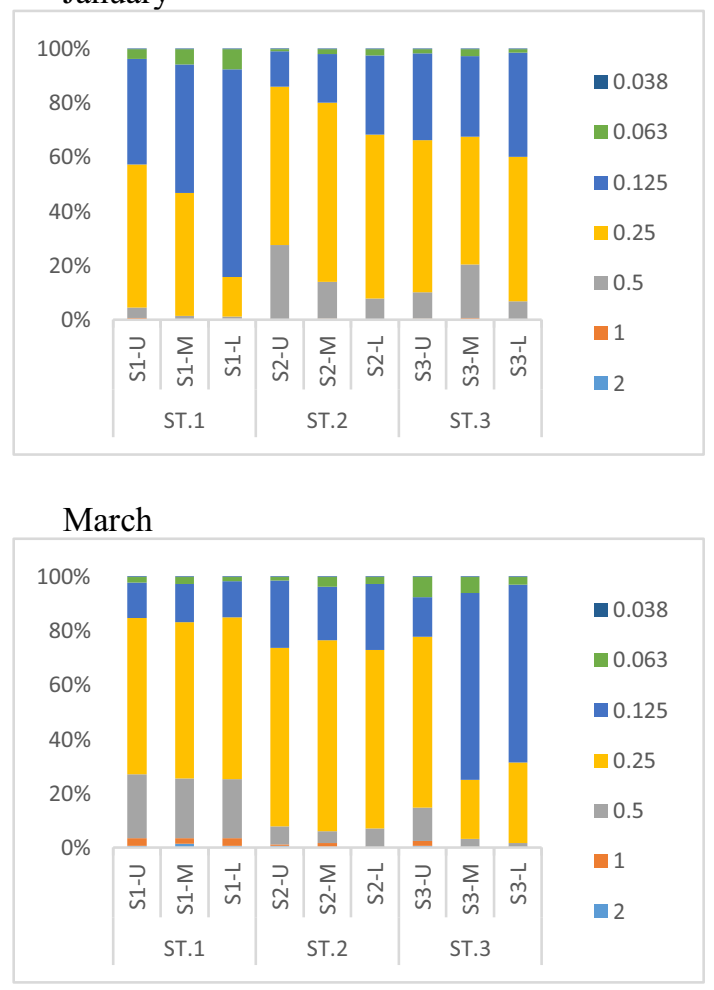

Fig. 1. Percentage of sediment fraction period.

\section{Results and Discussion}

The percentage of sediment weight for each grain size fraction was obtained from the sediment sieving process. The medium sand fraction has the highest percentage. The percentage of coarse sand was relatively high in November, followed by the percentage of fine sand. In the following period, January and March, the percentage of medium sand was seen to be lower, while the percentage of fine sand was higher than the results obtained in November. The weight percentage of each sediment from the three locations is presented in Figure 2.

The information on the percentage weight per fraction (from Figure 2), was used to calculate the mean grain size (MGS). The MGS value was processed arithmetically based on the layer and sample collection period. From Table 1 it is assumed that there was a spatial variation in the MGS value in Lhoong, which roughly mean that station 3 has coarser grains than stations 1 and 2. MGS variation itself is common in profiles along the beach, which can be caused by beach morphology [30] as well as coastal slope and wave effects [31].

Table 1. Mean grain size value (in millimeter)

\begin{tabular}{|c|c|c|c|c|c|}
\hline \multirow{2}{*}{ Layer } & \multirow{2}{*}{ St. } & \multicolumn{3}{|c|}{ MGS (mm) } & Average \\
\cline { 3 - 6 } & & Nov & Jan & Mar & \\
\hline $\begin{array}{c}\text { Upper } \\
(0-5 \\
\mathrm{cm})\end{array}$ & 1 & 0.29 & 0.20 & 0.32 & 0.27 \\
\cline { 2 - 6 } & 2 & 0.28 & 0.30 & 0.24 & 0.27 \\
\cline { 2 - 6 } & 3 & 0.49 & 0.23 & 0.27 & 0.33 \\
\hline \multirow{2}{*}{$\begin{array}{c}\text { Mid } \\
(5-10 \\
\mathrm{cm})\end{array}$} & 1 & 0.29 & 0.18 & 0.32 & 0.26 \\
\cline { 2 - 6 } & 2 & 0.30 & 0.26 & 0.24 & 0.27 \\
\cline { 2 - 6 } & 3 & 0.68 & 0.26 & 0.16 & 0.37 \\
\hline $\begin{array}{c}\text { Lower } \\
(10-15 \\
\mathrm{cm})\end{array}$ & 1 & 0.30 & 0.14 & 0.31 & 0.25 \\
\cline { 2 - 6 } & 2 & 0.34 & 0.22 & 0.23 & 0.26 \\
\cline { 2 - 5 } & 3 & 0.52 & 0.21 & 0.16 & 0.30 \\
\hline
\end{tabular}

The variation in MGS values on the Lhoong beach can be assumed to be related to wave activity, as well as the situation on this beach which faces the Indian Ocean. However, this effect can differ between seasons, as previously mentioned [32], that seasons control the variation of wave energy and then affect the MGS value. Moreover, in the swash area, the seasons also make a difference to the sediment transport mechanism that occurs [17], [33]. The variation of MGS at all stations was the highest at November compared to January and March, according to the obtained standard deviation value (Figure3). The highest MGS value in November can be attributed to the seasonal pattern that occurs in the western waters of Aceh. The first data collection was carried out in November and was in the transition season from the southwest to the northeast monsoon [34], so that before data collection was carried out, Lhoong beach had experienced the previous southwest monsoon period. The southwest monsoon in Aceh provides high energy exposure, especially the west coast of Aceh, since the dominant wind comes from the Indian Ocean [27], [35]. We speculated that the presence of high energy during the previous period still has an influence 
on the grain size during the observation period, and the presence of a high standard deviation is also a consequence of the transitional phase or transitional season that was occurring at the time of data collection. Furthermore, from Figure 3, it can also be seen that the MGS value in January was lower and slightly increased again in March. The January period was more correlated with the northeast monsoon, where the west coast of Aceh experienced calmer conditions than the southwest monsoon. Likewise, the standard deviation value also seemed to follow the trend, where the standard deviation value in January was quite small.

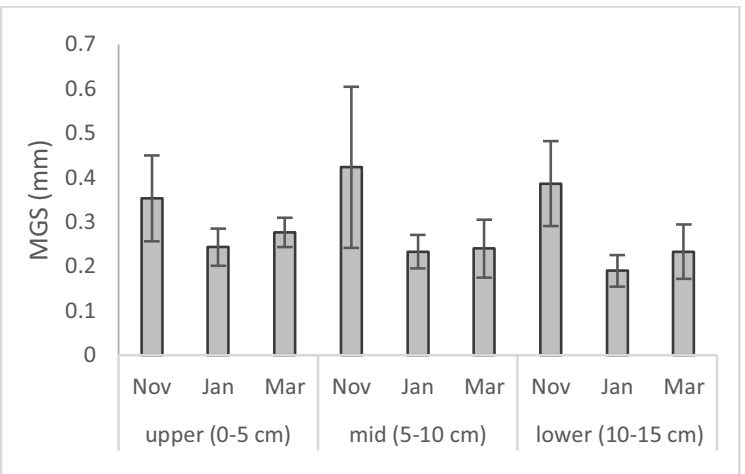

Fig. 3. MGS value based on depth layer

The pattern of sediment transport in the swash area is quite complex [36], since the phenomenon of sediment flow in this area is influenced by the interaction of waves and backwash [37]. Based on vertical layering, we also suspected that there was a seasonal effect. Furthermore, the mean value of standard deviation per layer showed that the highest value was obtained from the middle layer. We could not find out the details of the process that has formed the highest standard deviation values in the middle layer $(5-10 \mathrm{~cm})$, as we suspected the greatest variation should occur in the surface layer. However, we assumed that this is related to a transitional process of depositional composition, which at the end of the southwest monsoon would make the finer grains more likely to settle on the seabed. The presence of waves on the beach will more easily carry and stir the fine particles into water column [38]. Furthermore, the stirring process and the deposition of fine sediment that occurred can directly affect the variation in grain size on the seabed even in the deeper layers, as the 10-15 cm layer also has a higher standard deviation value than the surface area.

\section{Conclusion}

Different observation periods responded to the mean grain size value at three locations on the Lhoong beach. The November period produced the coarsest grains compared to the January and March periods, in line with the standard deviation which was also quite high in November. Vertically, the sediment layering showed an influence from the observation period, where the midlayer produced sediment with the coarsest grains, along with the highest standard deviation compared to the lower $(10-15 \mathrm{~cm})$ and upper $(0-5 \mathrm{~cm})$ layers.
Acknowledgments. The writing of this manuscript is supported by the Matching Fund - Kedaireka funded by the Ministry of Education, Culture, Research, and Technology Indonesia awarded to the Research Center for Marine Sciences and Fisheries, Universitas Syiah Kuala.

\section{References}

1. J. Obu, H. Lantuit, G. Grosse, F. Günther, T. Sachs, V. Helm, and M. Fritz, Geomorphology 293, 331 (2017)

2. C. Armaroli and P. Ciavola, Geomorphology 126, 201 (2011)

3. N. A. Berard, R. P. Mulligan, A. M. F. da Silva, and M. Dibajnia, Coast. Eng. 125, 70 (2017)

4. G. Incelli, N. Dodd, C. E. Blenkinsopp, F. Zhu, and R. Briganti, Coast. Eng. 115, 42 (2016)

5. R. T. McCall, G. Masselink, T. G. Poate, J. A. Roelvink, L. P. Almeida, M. Davidson, and P. E. Russell, Coast. Eng. 91, 231 (2014)

6. N. Cohn and P. Ruggiero, Coast. Eng. 115, 79 (2016)

7. H. Sawada, H. Saito, K. Adachi, and H. Toyohara, J. Sea Res. 65, 275 (2011)

8. M. C. Menéndez, C. A. Baleani, M. R. Amodeo, E. M. Acha, and M. C. Piccolo, Estuar. Coast. Shelf Sci. 227, 106307 (2019)

9. A. Anandkumar, R. Nagarajan, E. Sellappa Gounder, and K. Prabakaran, Chemosphere 287, 132069 (2022)

10. R. Ranasinghe, M. Larson, and J. Savioli, Coast. Eng. 57, 1006 (2010)

11. A. H. Reis and C. Gama, Geomorphology 114, 276 (2010)

12. E. P. Beetham and P. S. Kench, Geomorphology 209, 98 (2014)

13. K. F. Nordstrom, J. Sediment. Res. 47, 1287 (1977)

14. G. M. Curtiss, P. D. Osborne, and A. R. HornerDevine, Mar. Geol. 259, 73 (2009)

15. A. Ribal, A. V Babanin, S. Zieger, and Q. Liu, Renew. Energy 160, 1349 (2020)

16. G. Yang, X. H. Wang, Y. Zhong, Z. Cheng, and F. P. Andutta, Estuar. Coast. Shelf Sci. 244, 106931 (2020)

17. J. M. Alsina, J. van der Zanden, I. Cáceres, and J. S. Ribberink, Coast. Eng. 140, 23 (2018)

18. T. E. Baldock, J. A. Alsina, I. Caceres, D. Vicinanza, P. Contestabile, H. Power, and A. Sanchez-Arcilla, Coast. Eng. 58, 214 (2011)

19. N. Senechal and A. Ruiz de Alegría-Arzaburu, in edited by D. W. T. Jackson and A. D. B. T.-S. B. M. Short (Elsevier, 2020), pp. 461-486

20. S. J. Kulkarni, P. G. Deshbhandari, and K. S. Jayappa, Aquat. Procedia 4, 117 (2015)

21. K. D'Haen, G. Verstraeten, and P. Degryse, Prog. Phys. Geogr. Earth Environ. 36, 154 (2012) 
22. H. E. Wittmeier, J. Bakke, K. Vasskog, and M. Trachsel, Quat. Sci. Rev. 114, 78 (2015)

23. K. M. Zahid and D. L. Barbeau, Sediment. Geol. 229, 64 (2010)

24. R. Jagodziński, B. Sternal, W. Szczuciński, C. Chagué-Goff, and D. Sugawara, Sediment. Geol. 282, 57 (2012)

25. S. Purnawan, N. Ihsan, I. Setiawan, and S. Yuni, Depik 7, 22 (2018)

26. S. Purnawan, I. Setiawan, H. A. Haridhi, and M. Irham, IOP Conf. Ser. Earth Environ. Sci. 106, (2018)

27. I. Setiawan, S. Rizal, Y. Haditiar, Y. Ilhamsyah, S. Purnawan, M. Irham, and S. Yuni, in IOP Conf. Ser. Earth Environ. Sci. 176 (IOP Publishing, Bogor, 2018), p. 012016

28. ASTM, D4823-95 Standard Guide for Core Sampling Submerged, Unconsolidated Sediments (ASTM International, West Conshohocken, 2014)

29. C. K. Wentworth, J. Geol. 30, 377 (1922)

30. A. H. F. Klein, Ó. Ferreira, J. M. A. Dias, M. G. Tessler, L. F. Silveira, L. Benedet, J. T. de Menezes, and J. G. N. de Abreu, Coast. Eng. 57, 98 (2010)

31. S. Sharma, V. S. Kumar, and R. Gowthaman, Mar. Georesources Geotechnol. 35, 887 (2017)

32. M. Samsuddin, J. Coast. Res. 5, 57 (1989)

33. J. M. Alsina, I. Cáceres, M. Brocchini, and T. E. Baldock, Coast. Eng. 68, 31 (2012)

34. I. Imanullah, S. Sofyan, S. Sugianto, Y. Haditiar, and S. Rizal, IOP Conf. Ser. Earth Environ. Sci. 348, 12066 (2019)

35. S. Rizal, I. Setiawan, T. Iskandar, Y. Ilhamsyah, A. W. Mulyadi, and M. Musman, Sains Malaysiana 39, 519 (2010)

36. P. Chardón-Maldonado, J. C. Pintado-Patiño, and J. A. Puleo, Coast. Eng. 115, 8 (2016)

37. J. van der Zanden, I. Cáceres, S. Eichentopf, J. S. Ribberink, J. J. van der Werf, and J. M. Alsina, Coast. Eng. 152, 103519 (2019)

38. L. Zuo, D. Roelvink, Y. Lu, and G. Dong, Int. J. Sediment Res. (2021) 